\title{
Modeling and Optimizations of Phosphate Removal from Aqueous Solutions Using Synthetic Zeolite Na-A
}

\author{
E. A. Mohamed, A. Q. Selim, M. K. Seliem, Mostafa R. Abukhadra \\ Geology Department, Faculty of Science, Beni-Suef University, Beni-Suef, Egypt \\ Email: Geomostafa89@yahoo.com
}

Received 4 August 2015; accepted 5 September 2015; published 8 September 2015

Copyright (C) 2015 by authors and Scientific Research Publishing Inc.

This work is licensed under the Creative Commons Attribution International License (CC BY). http://creativecommons.org/licenses/by/4.0/

\section{(c) (i) Open Access}

\section{Abstract}

Synthetic zeolite Na-A was prepared from Egyptian kaolinite by hydrothermal treatment to be used as an adsorbent for removal of phosphate from aqueous solutions. The present work deals with the application of response surface methodology (RSM) and central composite rotatable design (CCRD) for modeling and optimization of the effect of four operating variables on the removal of phosphate from aqueous solution using zeolite $\mathrm{Na}-\mathrm{A}$. The parameters were contact time $(0.5-6$ h), phosphate anion concentrations $(10-30 \mathrm{mg} / \mathrm{L})$, adsorbent dosage $(0.05-0.1 \mathrm{~g})$, and solution pH (2 - 7). A total of 26 tests were conducted using the synthetic zeolite Na-A according to the conditions predicted by the statistical design. In order to optimize removal of phosphate by synthetic zeolite Na-A, mathematical equations of quadratic polynomial model were derived from Design Expert Software (Version 6.0.5). Such equations are second-order response functions which represent the amount of phosphate adsorbed $(\mathrm{mg} / \mathrm{g})$ and the removal efficiency (\%) and are expressed as functions of the selected operating parameters. Predicted values were found to be in good agreement and correlation with experimental results $\left(R^{2}\right.$ values of 0.918 and 0.905 for amount of phosphate adsorbed and removal efficiency of it, respectively). To understand the effect of the four variables for optimal removal of phosphate using zeolite $\mathrm{Na}-\mathrm{A}$, the models were presented as cube and 3-D response surface graphs. RSM and CCRD could efficiently be applied for the modeling of removing of phosphate from aqueous solution using zeolite $\mathrm{Na}-\mathrm{A}$ and it is efficient way for obtaining information in a short time and with the fewer number of experiments.

\section{Keywords}

Zeolite Na-A, Hydrothermal, Phosphate, Optimization 


\section{Introduction}

Wastewater is one of the biggest environmental problems all over the world [1]. It is usually hazardous to human populations and the environment and it is critical to be treated prior to disposal into streams, lakes, seas, and land surfaces [2]. Surface waters contain certain level of phosphorus (P) in various compounds, which is an important constituent of living organisms [1]. Phosphorus (P) is a major limiting nutrient for the growth of phytoplankton including cyanobacteria causing eutrophication [3] [4].

Increasing the phosphorous concentration resulted in impairing the water quality and causing many problems as cloudy lakes, depletion of oxygen in deep water in lakes, high purification costs, decreased recreational and conservation value of water bodies, loss of livestock and the possible lethal effect of algal toxins on drinking water [5]. Controlling phosphorous pollutions is critical for agriculture environmental protection and water environment quality development [6]-[8].

There are several methods which have been applied to eliminate phosphorous in waste water including chemical precipitation, biological removal, crystallization, adsorption and ion exchange [9]-[11]. Phosphorus adsorption is the main technology for phosphorus co-precipitation; the process involves adsorption of phosphorus onto the surface of the co-precipitant, followed by a slow incorporation of phosphorus into the structure of the adsorptive material to scavenge phosphorus from the water [12]. Co-precipitant materials for phosphate removal include limestone, gypsum, fly ash and natural calcite [13] [14], but such material has low adsorption capacities [4]-[15].

Zeolite molecular sieves are crystalline microporousaluminosilicates with an indefinitely extending threedimensional network of $\mathrm{AlO}_{4}$ and $\mathrm{SiO}_{4}$ tetrahedrons linked by sharing of oxygen atoms [16]. Zeolite minerals are characterized by high surface area, rigid three-dimensional structures free of swelling behavior and high cation exchange capacity [17]; therefore, zeolites exhibit amazing sorption and hydraulic properties and commonly used in waste water remediation [18].

Zeolites are usually synthesized under hydrothermal conditions from basic aluminosilicate precursor gels at elevated temperatures [19] [20]. Zeolites were synthesized using different materials such as carbonized rice husk [21], low-grade natural kaolin [22], natural and modified diatomite [16], kaolinite [23], rice husk [24], rice husk ash and metakaolin [25], fly ash [26], paper sludge ash [27], chrysotile and rice husk [28] and rectorite mineral [29]. The A-type zeolite is one of the most common synthetic zeolites which have various applications in industry as catalysis, separation, ion exchange and adsorption [30] (Xing-dong et al., 2013). Synthetic zeolites can be used as adsorbents or substitute for sodium tri-polyphosphate [31] [32].

The aim of this paper focuses on applying, response surface methodology (RSM) and statistical Central Composite Rotatable Design (CCRD) to evaluate the interactive effect of the selected factors and to obtain the optimum conditions for maximum removal of phosphate from aqueous solution by synthetic zeolite Na-A from Egyptian kaolinite.

\section{Statistical Experimental Design}

\subsection{Response Surface Methodology (RSM)}

Response Surface Methodology (RSM) is a collection of mathematical and statistical techniques used in significance of several affecting factors in an optimum manner, even in the presence of complex interactions [33]. The main reason for implementing RSM is to determine the optimum operational conditions for the process or to determine a region that satisfies the operating specifications [34]. Response Surface Methodology (RSM) attracted the attention of many researchers as a result of its advantages in reducing the number of experiments, understanding the pattern in which the measured response is affected by any changes in the selected variables [35]. The main advantage of RSM is that it enables the improvement of the product from predicted property values and its ability to predict the interactions of more than two or more factors (interactive effects) and effects due to collective contributions of the measured response. If the selected variables are assumed to be measurable, the response surface can be expressed as follows [36]:

$$
Y=f\left(X_{1}, X_{2}, X_{3}, \cdots, X_{k}\right)
$$

where $y$ is the answer of the system, and $x_{i}$ the variables of action called factors. The goal is to optimize the response variable $(y)$. The task then is to find a suitable approximation for the true functional relationship between independent variables and the response surface [36]. Usually a second-order model is utilized in response sur- 
face methodology:

$$
Y=\beta_{0}+\sum_{i=1}^{k} \beta_{i} X_{i}+\sum_{i=1}^{k} \beta_{i i} X_{i}^{2}+\sum_{i=1}^{k-1} \sum_{j=i+1}^{k} \beta_{i j} X_{i} X_{j}
$$

where $Y$ is the predicted response; $X_{1}, X_{2}, \cdots, X_{k}$ are input factors which influence the response $y$; $\beta_{0}$ is constant; $\beta_{i}$ is linear term coefficients; $\beta_{i i}$ is quadratic term coefficients; $\beta_{i j}$ is cross product term coefficients and $K$ is the number of factors.

\subsection{Central Composite Rotatable Design (CCRD)}

The experimental design techniques commonly used for process analysis and modeling are the full factorial, partial factorial and central composite rotatable designs. Central composite rotatable design originally developed by Box and Wilson (1951) [37] and improved upon by Box and Hunter (1957) [38]. CCRD gives almost as much information as a three-level factorial, requires many fewer tests than the full factorial design and has been shown to be sufficient to describe the majority of steady-state process responses [39] [40]. Hence in this study, it was decided to use CCRD to design the experiments. The number of tests required for CCRD includes the standard $2 k$ factorial with its origin at the center, $2 k$ points fixed axially at a distance, say $\beta$, from the center to generate the quadratic terms, and replicate tests at the center; where $k$ is the number of variables. The axial points are chosen such that they allow rotatability [38], which ensures that the variance of the model prediction is constant at all points equidistant from the design center. Replicates of the test at the center are very important as they provide an independent estimate of the experimental error. The number of experiments can be detected easily through the following equation: $N=K^{k}+2 K+c p$ where $(k)$ is the variable number and $(c p)$ is the number of central points [41] [42].

\section{Experimental Work}

\subsection{Materials}

The starting kaolinite clay sample used in the present study was supplied by Central Metallurgical Research and Development Institute, CMRDI, Cairo, Egypt. Its chemical composition is $45 \% \mathrm{SiO}_{2}, 35 \% \mathrm{Al}_{2} \mathrm{O}_{3}, 3.5 \% \mathrm{TiO}_{2}$, $1.5 \% \mathrm{Fe}_{2} \mathrm{O}_{3}, 0.1 \% \mathrm{MgO}, 0.6 \% \mathrm{CaO}, 0.3 \% \mathrm{Na}_{2} \mathrm{O}, 0.05 \% \mathrm{~K}_{2} \mathrm{O}$ and ignition loss nearly $14 \%$. The alkali hydroxide used in the synthesis of zeolite $\mathrm{A}$ is $\mathrm{NaOH}$ (Alfa Aesar, purity: 97\%).

\subsection{Synthesis of Zeolite Na-A}

Metakolinization is the process in which kaolinite was subjected to calcination at high temperature of about $650^{\circ}$ $\mathrm{C}$ for $5 \mathrm{~h}$ where by dehydroxylation occurs forming amorphous more reactive product (metakaolinite). ZeoliteNa-A was synthesized using Egyptian kaolin and sodium hydroxide by treatment of metakaolinite with sodium hydroxide solution with 1:2 weight ratio with a continuous vigorous stirring of the mixture overnight at room temperature. After stirring, the mixture was transferred to $125 \mathrm{ml}$ stainless steel Parr reactors and heated in an oven at $100^{\circ} \mathrm{C}$ for $8 \mathrm{~h}$. After hydrothermal treatment, the vessels were cooled down to room temperature. The contents from Teflon vessels were centrifuged to separate solids and solutions. Then, the solid products were washed with distilled water to remove the excess alkalinity and dried at $65^{\circ} \mathrm{C}$.

\subsection{Sample Characterization}

X-ray powder diffraction patterns were obtained using a Philips APD-3720 diffractometer with Cu Ka radiation, operated at $20 \mathrm{~mA}$ and $40 \mathrm{kV}$ in the $2 \theta$ range of $5-70$ at a scanning speed of $5 \% \mathrm{~min}$. Scanning electron microscopy using a field emission scanning electron microscope (JSM-6510, JEOL, Tokyo, Japan). Particle size analyses and surface area of the syntheticzeolite Na-A were determined by BT-2001 (wet) laser particle size analyzer device.

\subsection{Adsorption Experiments}

Response surface design and central composite rotatable design of quadratic model has been designed according to fours elected variables (Contact time, initial concentration of phosphate, Dosage and $\mathrm{pH}$ ) to modeling and 
detect the optimum conditions under which, maximum removal of phosphate from aqueous solution can be occurred. The upper and lower limits for the selected variables in the actual and coded values set in (Table 1). Phosphate stock solutions were prepared by dissolving sodium phosphate dibasic dehydrate in distill water according to the concentrations suggested by the experimental design (Table 2) $\mathrm{pH}$ values were adjusted using dilute nitric acid and ammonia solutions.

Table 1. The level and range of independent variables chosen for removal of phosphate from aqueous solution.

\begin{tabular}{cccccc}
\hline Factor & Name & Low actual & High actual & Low coded & High coded \\
\hline A & Contact time & $0.5 \mathrm{~h}$ & $6 \mathrm{~h}$ & -1 & 1 \\
B & Phosphate concentrations & $50 \mathrm{ml} \cdot \mathrm{gm}$ & $250 \mathrm{ml} \cdot \mathrm{gm}$ & -1 & 1 \\
C & Dosage & $0.05 \mathrm{gm}$ & $0.1 \mathrm{gm}$ & -1 & 1 \\
D & $\mathrm{pH}$ & 2 & 7 & -1 & 1 \\
\hline
\end{tabular}

Table 2. Results of the experimental runs designed according to the CCRD.

\begin{tabular}{|c|c|c|c|c|c|c|}
\hline Run & Contact time (A) & Initial concentration $(\mathrm{mg} / \mathrm{L})(B)$ & Dosage (C) & pH (D) & Uptake (mg/g) & Removal efficiency (\%) \\
\hline 1 & 6.00 & 50.00 & 0.05 & 2.00 & 10 & 20 \\
\hline 2 & 6.00 & 50.00 & 0.10 & 7.00 & 15 & 30 \\
\hline 3 & 3.00 & 150.00 & 0.08 & 7.00 & 12 & 8 \\
\hline 4 & 0.50 & 50.00 & 0.10 & 7.00 & 9 & 18 \\
\hline 5 & 3.00 & 50.00 & 0.08 & 4.00 & 30 & 60 \\
\hline 6 & 0.50 & 250.00 & 0.05 & 7.00 & 10 & 4 \\
\hline 7 & 0.50 & 50.00 & 0.05 & 2.00 & 6 & 12 \\
\hline 8 & 6.00 & 50.00 & 0.05 & 7.00 & 7 & 12 \\
\hline 9 & 0.50 & 250.00 & 0.10 & 7.00 & 19 & 7.6 \\
\hline 10 & 6.00 & 250.00 & 0.05 & 2.00 & 12 & 4.8 \\
\hline 11 & 0.50 & 50.00 & 0.10 & 2.00 & 13 & 26 \\
\hline 12 & 6.00 & 250.00 & 0.05 & 7.00 & 8 & 3.2 \\
\hline 13 & 6.00 & 250.00 & 0.10 & 7.00 & 18 & 6.8 \\
\hline 14 & 3.00 & 150.00 & 0.05 & 4.00 & 29 & 19.3 \\
\hline 15 & 0.50 & 150.00 & 0.08 & 4.00 & 23 & 15.3 \\
\hline 16 & 3.00 & 150.00 & 0.08 & 4.00 & 48 & 32 \\
\hline 17 & 0.50 & 250.00 & 0.05 & 2.00 & 15 & 6 \\
\hline 18 & 3.00 & 150.00 & 0.10 & 4.00 & 53 & 35.33 \\
\hline 19 & 0.50 & 50.00 & 0.05 & 7.00 & 4 & 8 \\
\hline 20 & 6.00 & 250.00 & 0.10 & 2.00 & 34 & 13.6 \\
\hline 21 & 3.00 & 250.00 & 0.08 & 4.00 & 47 & 18.8 \\
\hline 22 & 6.00 & 150.00 & 0.08 & 4.00 & 49 & 32.6 \\
\hline 23 & 0.50 & 250.00 & 0.10 & 2.00 & 26 & 10.4 \\
\hline 24 & 6.00 & 50.00 & 0.10 & 2.00 & 25 & 50 \\
\hline 25 & 3.00 & 150.00 & 0.08 & 4.00 & 48 & 32 \\
\hline 26 & 3.00 & 150.00 & 0.08 & 2.00 & 18 & 12 \\
\hline
\end{tabular}


The experiments were performed according to tests suggested by the statistical design where $25 \mathrm{ml}$ from the prepared solutions shake with the suggested dosage for various contact times then the solutions filtered using 45 $\mu \mathrm{m}$ pore size What man filter paper. The results were evaluated by following phosphate concentration in the filtrate solutions using a spectrophotometric method (DIN EN 1189, 1996) at a wavelength of $700 \mathrm{~nm}$ with a Lamp 2 UV/VIS Spectrophotometer. The amount of phosphate ions adsorption onto the zeolite $(q(\mathrm{mg} / \mathrm{g}))$ and the removal efficiency were calculated as follows:

$$
\begin{gathered}
q=\frac{V\left(C_{0}-C_{e}\right)}{m} \\
\text { Removal efficiency }(\%)=\frac{100\left(C_{0}-C_{e}\right)}{100}
\end{gathered}
$$

where $C_{0}$ and $C_{e}$ are the ion concentrations in the initial solution and the solution after equilibration of phosphate ions, respectively. $V$ is the volume of solution in ( $\mathrm{ml}$ ) and $m$ is the mass of sorbent (gm).

The data obtained were fitted to a second-order polynomial equation:

$$
Y=\beta_{o}+\sum_{i=1}^{4} \beta_{i} X_{i}+\sum_{i=1}^{4} \beta_{i i} X_{i}^{2}+\sum_{i=1}^{3} \sum_{j=i+1}^{4} \beta_{i j} X_{i} X_{j} .
$$

where $Y$ is amount of phosphate uptake; $\beta_{0}, \beta_{i}, \beta_{i i}, \beta_{i j}$ are constant coefficients $X_{i}$ are the uncoded independent variables. Subsequent regression analyses, analyses of variance (ANOVA) and response surfaces were performed using the Design Expert Software (Version 6.0.5). Optimal reaction parameters for maximum removal were generated using the software's numerical optimization function.

\section{Results and Discussion}

\subsection{Characterizations of the Resulted Zeolite}

The XRD patterns of the used natural kaolin and metakaolin are shown in Figure 1. Kaolinite and quartz are the

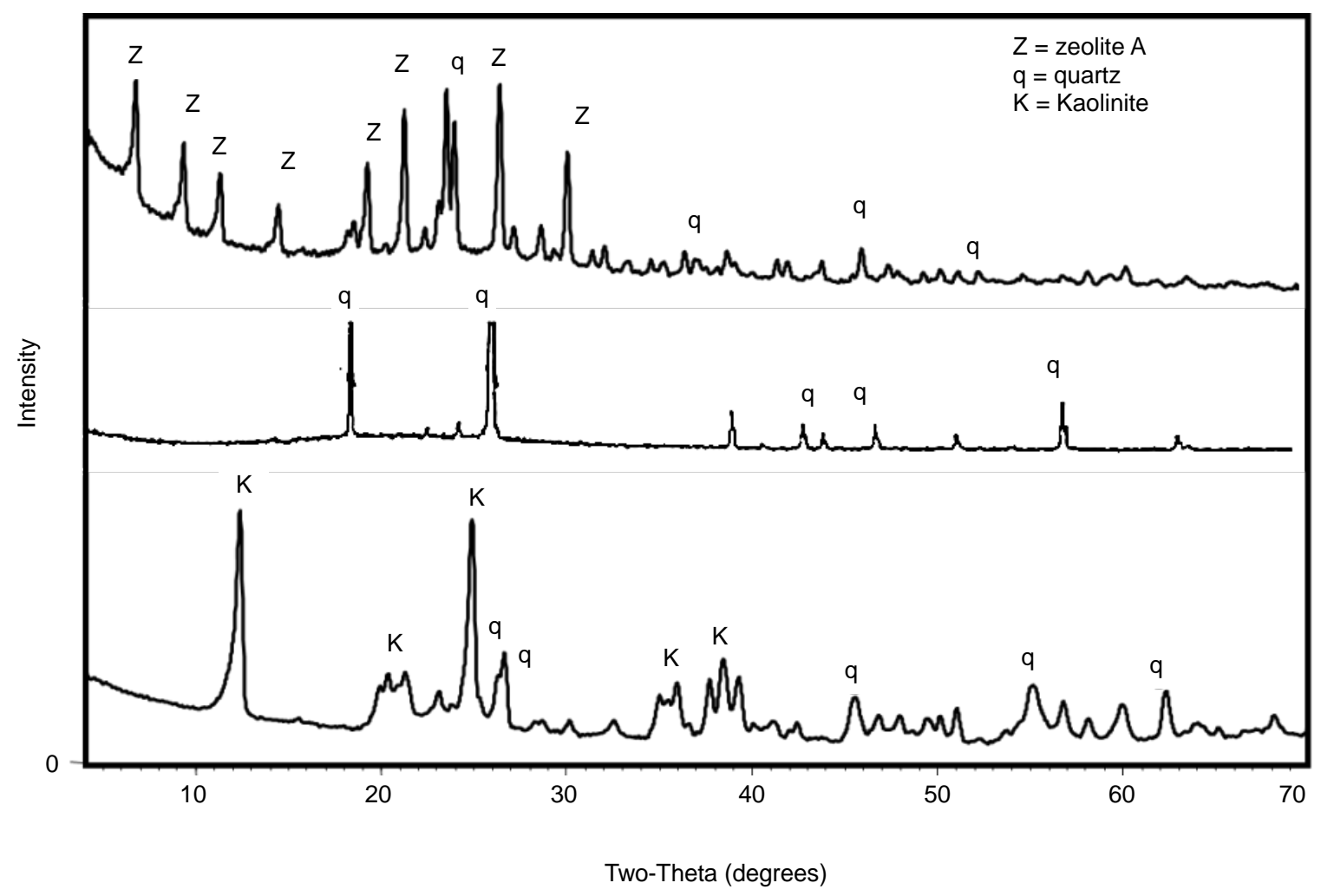

Figure 1. XDR patterns of raw kaolinite, metakaolinite and synthetic zeolite Na-A. 
main crystalline phases of untreated kaolin sample (Figure 1). Metakaolin was characterized by the absence of the main diffraction peaks of kaolin at $2 \theta$ values of $12.34^{\circ}$ and $24.64^{\circ}$ [43]. The main crystalline phase in metakaolin is corresponding to the presence of quartz (Figure 1). X-ray diffraction patterns of synthetic zeolite Na-A samples are shown in (Figure 1). From Figure 1, the synthesized products matched the main peaks of zeolite $\mathrm{Na}-\mathrm{A}$ at $2 \theta$ values of $7.2^{\circ}, 10.3^{\circ}, 12.6^{\circ}, 16.2^{\circ}, 21.8^{\circ}, 24^{\circ}, 26.2^{\circ}, 27.2^{\circ}, 30^{\circ}, 30.9^{\circ}, 31.1^{\circ}, 32.6^{\circ}, 33.4^{\circ}$ and $34.3^{\circ}$ that were reported by [44].

SEM images of zeolite Na-A synthesized by hydrothermal treatment of metakaolinite with sodium hydroxide show the transformation of kaolinite (Figure 2) to well-developed cubic crystals of zeolite Na-A (Figure 2). The SEM results of the present work are similar to those reported in previous studies [19] [23] [43]. The particle size analyses of the studied synthetic zeolite showed that $98 \%$ less than $15 \mu \mathrm{m}, 80 \%$ less than $9 \mu \mathrm{m}$, and $50 \%$ less than $5 \mu \mathrm{m}$ and the surface area gave value $683 \mathrm{~m}^{2} / \mathrm{g}$.

\subsection{Results of Adsorption Experiments}

Table 2 summarizes the experimental runs designed with the CCRD for removal of phosphate from aqueous solution using synthetic zeolite Na-A in terms of the independent variables (contact time, initial concentration, dosage, $\mathrm{pH}$ ) and the resulted responses (phosphate uptaking (mg) and removal efficiency (\%)). The interaction between the selected variables in addition to their effects on different responses are further illustrated.

\subsubsection{Fitness of the Statistical Model}

The results of analysis of variance (ANOVA) show that, the Model F-values for amount of phosphate uptaking and the removal efficiency are 8.88 and 8.16 respectively which imply that the model is significant; and there is only a $0.04 \%$ and $0.06 \%$ chances that a "Model F-Value" resulted from noise for the previous stated responses. Pure errors are zero which indicates very good reproducibility of the obtained data. The mathematical equations of the quadratic polynomial model, which represent the relations between the required responses $\left(q\left(Y_{1}\right)\right.$ and removal efficiency of phosphate $\left(Y_{2}\right)$ ) and the selected variables, were obtained from Design Expert Software (Version 6.0.5) for coded units as follows:

$$
\begin{aligned}
Y_{1}= & +42.77+2.86 X A+3.74 X B+6.25 X C-3.2 X D-4.43 X A^{2}-1.11 B^{2} \\
& +2.39 X C^{2}-25.50 X D^{2}-1.54 X A X B+1.30 X A X C-1.24 X A X D \\
& +1.00 X B X C-0.97 X B X D-1.68 X C X D \\
Y_{2}= & +30.75+3.62 X A-9.03 X B+6.12 X C-3.19 X D-6.05 X A^{2} \\
& +10.81 X B^{2}-1.29 X C^{2}-19.77 X D^{2}-2.83 X A X B+1.74 X A X C \\
& -1.35 X A X D-3.22 X B X C+1.99 X B X D-1.44 X C X D
\end{aligned}
$$

The observed (experimental) values and the predicted values obtained using the model equations are given in Table 3 . The predicted values were seen to be sufficiently correlated with the observed values and this reflected
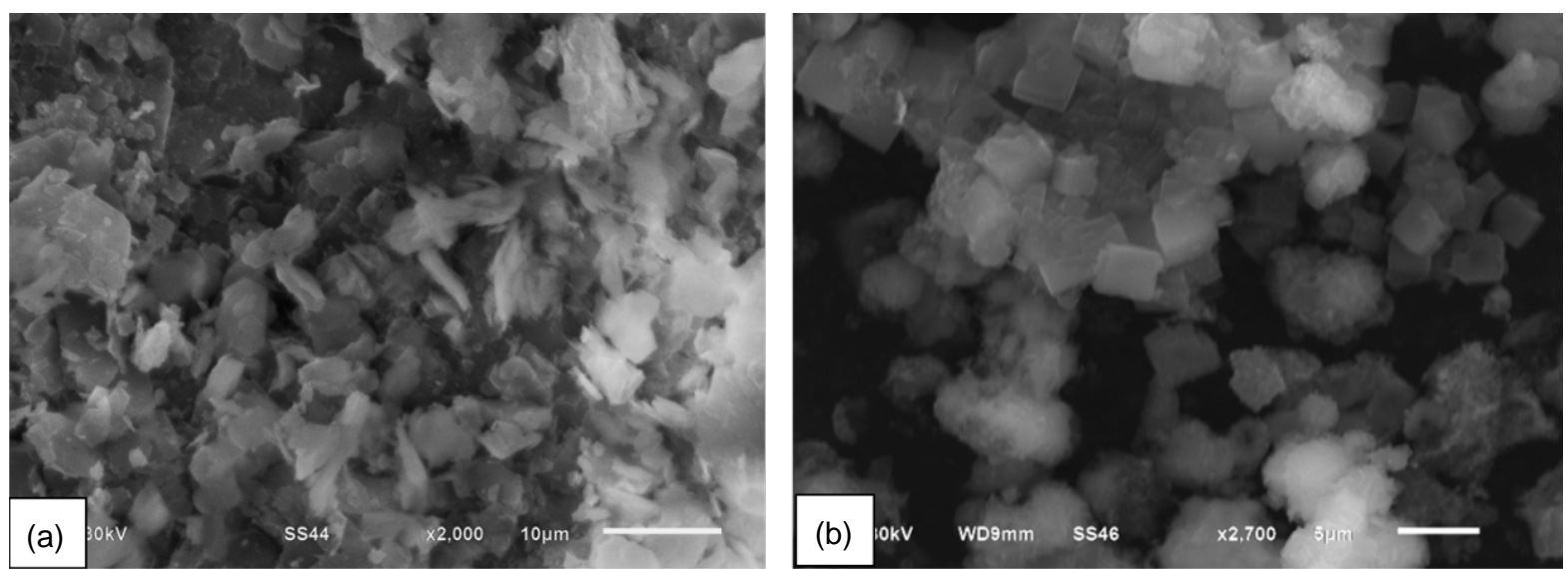

Figure 2. Scanning electron micrographs of kaolinite (a), and well-developed crystals of zeolite Na-A (b). 
Table 3. The predicted and observed values results from the treatment processes.

\begin{tabular}{|c|c|c|c|}
\hline \multicolumn{2}{|c|}{ Amount of phosphate uptaking (mg/g) } & \multicolumn{2}{|c|}{ Removal efficiency (\%) } \\
\hline Observed values & Predicted values & Observed values & Predicted values \\
\hline 12 & 14.41 & 12 & 11.8 \\
\hline 13 & 12.63 & 20 & 23.93 \\
\hline 25 & 26.52 & 6 & 1.89 \\
\hline 26 & 27.15 & 4.8 & 2.69 \\
\hline 34 & 34.86 & 26 & 29.89 \\
\hline 4 & 2.68 & 50 & 49 \\
\hline 7 & 6.41 & 10.4 & 7.08 \\
\hline 10 & 9.31 & 13.6 & 14.85 \\
\hline 8 & 6.86 & 8 & 7.05 \\
\hline 9 & 7.25 & 12 & 13.76 \\
\hline 15 & 16.16 & 4 & 5.08 \\
\hline 19 & 17.87 & 3.2 & 0.45 \\
\hline 17 & 20.61 & 18 & 19.36 \\
\hline 23 & 34.86 & 30 & 33.04 \\
\hline 49 & 41.08 & 7.6 & 4.49 \\
\hline 31 & 36.9 & 6.8 & 6.84 \\
\hline 47 & 45.05 & 15.3 & 20.66 \\
\hline 29 & 38 & 32.6 & 28.44 \\
\hline 56 & 50.94 & 62 & 50.17 \\
\hline 18 & 20.09 & 18.8 & 31.83 \\
\hline 12 & 13.85 & 19.3 & 22.65 \\
\hline 48 & 42.08 & 37.3 & 35.15 \\
\hline 48 & 42.08 & 12 & 13.67 \\
\hline 12 & 14.41 & 12 & 11.8 \\
\hline 13 & 12.63 & 20 & 23.93 \\
\hline 25 & 26.52 & 6 & 1.89 \\
\hline
\end{tabular}

in the high determination coefficient $\left(R^{2}\right)$. The closer the $R^{2}$ is to 1 , the better the model fits the experimental data, the less the difference between the predicted and the observed values. $R^{2}$ values are above 0.9 for all the required responses as appear in Figure 3(a) for the amount of phosphate adsorbed by synthetic zeolite Na-A and Figure 3(b) for the removal efficiency of phosphate from aqueous solution. This give indication about the significance of the quadratic polynomial model and it is sufficient to represent the actual relations between the required responses and the selected variables.

\subsubsection{Effect of Interaction between Operating Parameters}

Effect of the selected variables and the interaction between them during removal of phosphate from aqueous solutions using synthetic zeolite Na-A is expressed in $3 \mathrm{D}$ and cube response surface diagrams. Response surface plots in terms of two selected factors at any one time maintaining all other factors at fixed levels are suitable in understanding either the main or the interaction effects of these two factors and represented by 3D diagrams. The elliptical shape of the curve indicates good interaction of the two variables and circular shape indicates no interaction between the variables [45]. 
The interaction between all the selected variables at fixed $\mathrm{pH} 4$ and their effect on the amount of adsorbed phosphate (mg) and the removal efficiency is represented by cube graphs in Figure 4 and Figure 5 respectively. It is clear that the adsorption of phosphate $(\mathrm{mg} / \mathrm{g})$ by zeolite Na-A increase with increasing the contact time, applied dose and the initial phosphate concentrations; and the maximum quantity of phosphate anions removed by the synthetic zeolite Na-A occurs at the upper limits for such selected factors. While the removal efficiency (\%) increase with increasing the contact time and the applied dose but decrease with increasing the initial phosphate concentrations.

1) Interaction between contact time and $\mathrm{pH}$

Figure 6(a) shows 3D diagram for the interaction between the contact time and $\mathrm{pH}$ values. Plotting the interaction between the contact time and $\mathrm{pH}$ values was performed at central fixed amount of synthetic zeolite Na-A $(0.08 \mathrm{~g})$ and initial phosphate concentrations $(150 \mathrm{mg} / \mathrm{L})$. At any given $\mathrm{pH}$, the amount of the adsorbed phosphate by the synthetic zeolite Na-A increased with increasing the time. The resulted curve show slight slope after $4 \mathrm{~h}$ as compared to it from $0.5 \mathrm{~h}$ to $4 \mathrm{~h}$ i.e. slight variation in the amount of phosphate removed after $4 \mathrm{~h}$. The previous behavior is related to the availability of sorption sites from $0.5 \mathrm{~h}$ to $4 \mathrm{~h}$ and with time, the number of such active sited reduced which in turn make the adsorption capacity nearly constant [46]. The capacity of the adsorbent to uptake phosphate anions from the solution with time reach the maximum value at acidic $\mathrm{pH}$ between 4 and 4.5 and this concordant with [47].
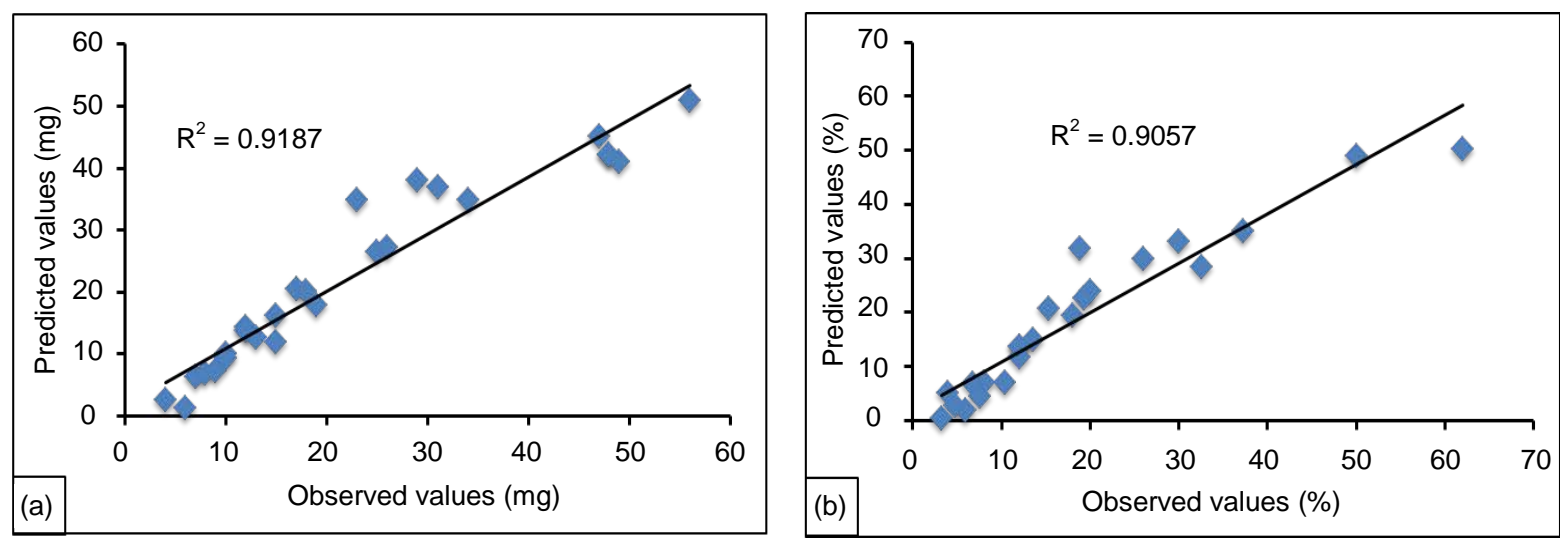

Figure 3. $R^{2}$ values for phosphate adsorption (mg/g) (a) and the removal efficiency (\%) (b).

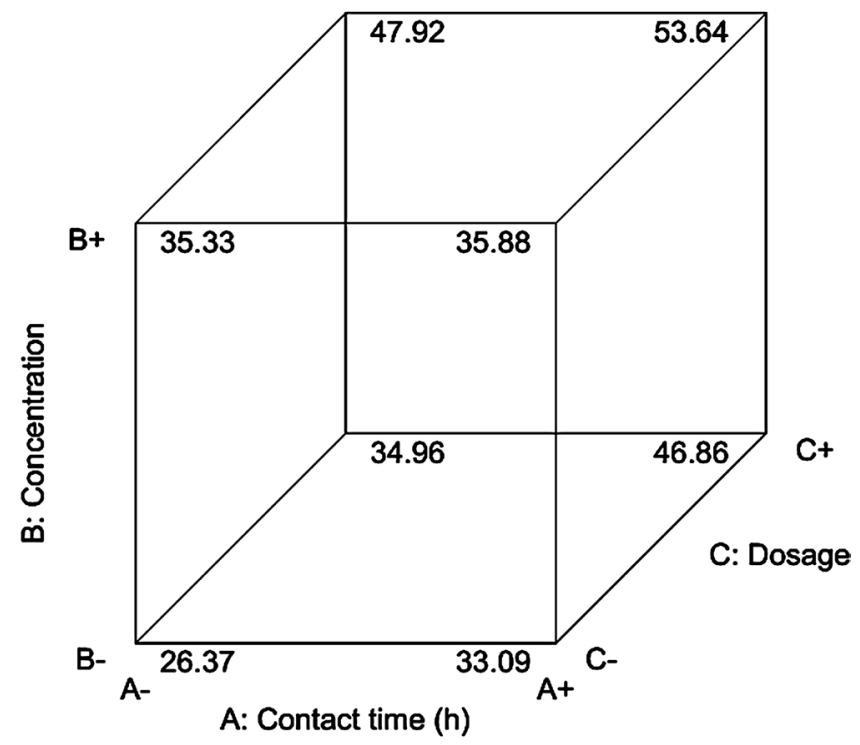

Figure 4. Cube graph for the interaction effect between the selected variables on the amount of adsorbed phosphate (mg/g) at $\mathrm{pH} 4$. 


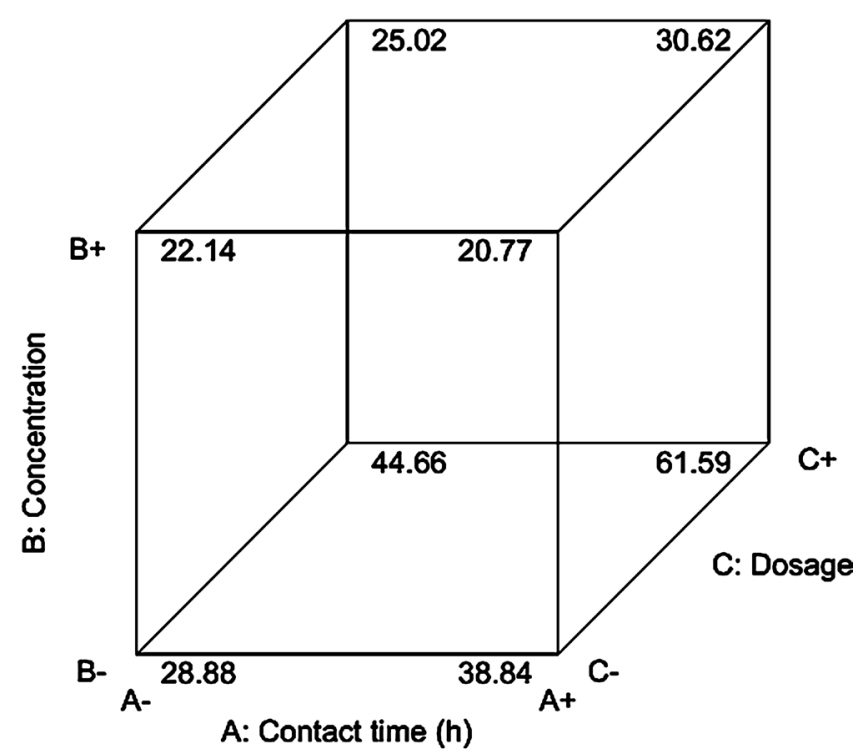

Figure 5. Cube graph for the interaction effect between the selected variables on the removal efficiency (\%) at $\mathrm{pH} 4$.

Effect of $\mathrm{pH}$ appears in increasing the adsorption capacity with $\mathrm{pH}$ values from $\mathrm{pH} 2$ to $\mathrm{pH} 4.5$ and then reduced from 4.5 to 7 . The optimum $\mathrm{pH}$ value for maximum capacity is detected to be from 4 to 4.5 . Acidic $\mathrm{pH}$ is preferred in removal phosphate anions, due to a greater number of surface sites with a PZC $=5.5$ at such conditions [48]. The maximum amount phosphate adsorbed at the optimum $\mathrm{pH}$ occurs after $4.5 \mathrm{~h}$ as contact time.

2) Interaction between initial phosphate concentration and $\mathrm{pH}$

The interaction between initial phosphate concentration and $\mathrm{pH}$ values was plotted in Figure 6(b) at fixed dosage $(0.08 \mathrm{gm})$ and contact time $(3 \mathrm{~h})$. The amount of adsorbed phosphate anions $(\mathrm{mg} / \mathrm{g})$ increased sharply with the initial phosphate concentration at any given $\mathrm{pH}$. Adsorption rate at lower phosphate concentrations is higher as compared to those at higher initial phosphate concentrations specially above $150 \mathrm{mg} / \mathrm{L}$ due to the high affinity of the binding sites for phosphate ions and availability of active sorption sites at lower concentrations [45]-[49]. $\mathrm{pH}$ values between 4 and 4.5 still the optimum conditions for maximum removal of phosphate anions at any given initial concentration.

Increasing the initial phosphate concentrations has reversible effect on the removal efficiency (\%) (Figure 6(c)). Such behavior may be attributed to the adsorption capacity of the synthetic zeolite Na-A. Increasing the initial phosphate concentrations provide more phosphate ions, while the fixed amount from the used adsorbent has a fixed number of sorption sites. Therefore the maximum uptake $(\mathrm{mg} / \mathrm{g})$ occur at the upper limit for the initial concentrations, while the maximum removal efficiency (\%).

3) Interaction between solid dosage and $\mathrm{pH}$

Figure 6(d) represents the response surface plotting of the interaction between the amount of zeolite Na-A (gm) and $\mathrm{pH}$ values at fixed contact time $(3 \mathrm{~h})$ and initial phosphate concentrations $(150 \mathrm{mg} / \mathrm{L})$. Quantities of adsorbed phosphate anions by zeolite increased with increasing adsorbent dose at any given $\mathrm{pH}$. This related to the increase in the total surface area of the adsorbent particles and the available sorption active sites [1]-[50]. Middle $\mathrm{pH}$ from 4 to 4.5 still the optimum $\mathrm{pH}$. The maximum capacity for phosphate uptaking and the best conditions for maximum removal efficiency (\%) (mg/g) occurs within this range and at the upper limit for the amount of the zeolite.

4) Interaction between adsorbent dosage and the contact time

The relation between amounts of zeolite Na-A and contact times during the adsorption process represented in Figure 7(a). The interaction effect was performed at fixed $\mathrm{pH}(4.5)$ and initial concentration $(150 \mathrm{mg} / \mathrm{L})$. The resulted curve revealed that the adsorption capacity increase with increasing both the contact time and the amount of zeolite. The interaction effect appears in increasing the effect of the contact time with increasing the dose to the maximum value at $0.1 \mathrm{gm}$. The maximum effect for the amount of zeolite occur after $4.5 \mathrm{~h}$ then the efficiency reduced i.e. $0.1 \mathrm{gm}$ dose and $4.5 \mathrm{~h}$ contact time are the optimum conditions. 


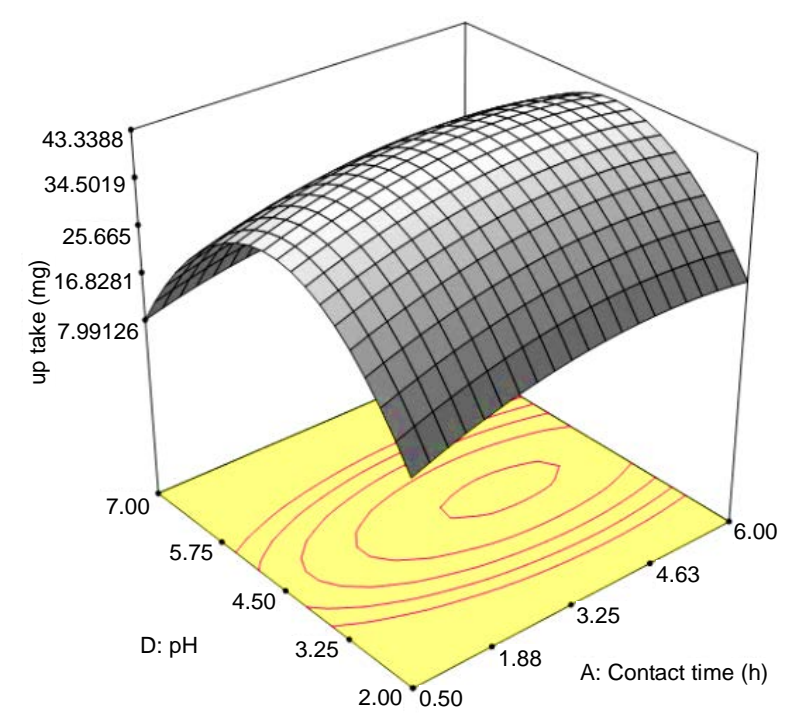

(a)

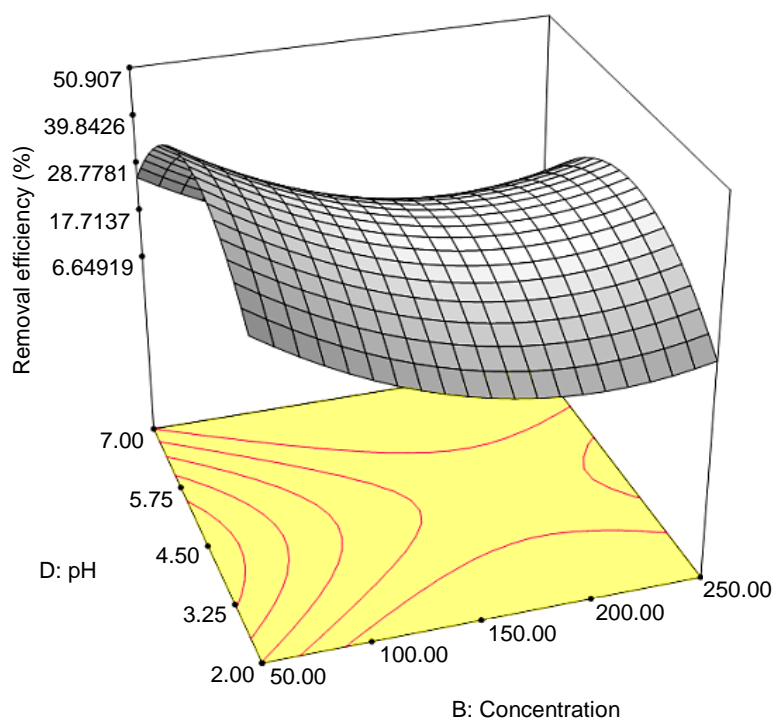

(c)

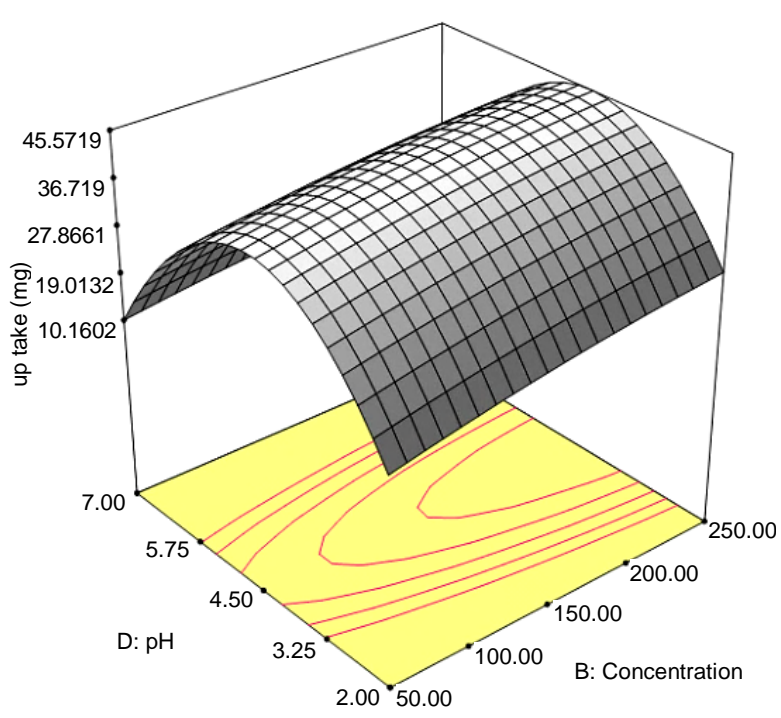

(b)

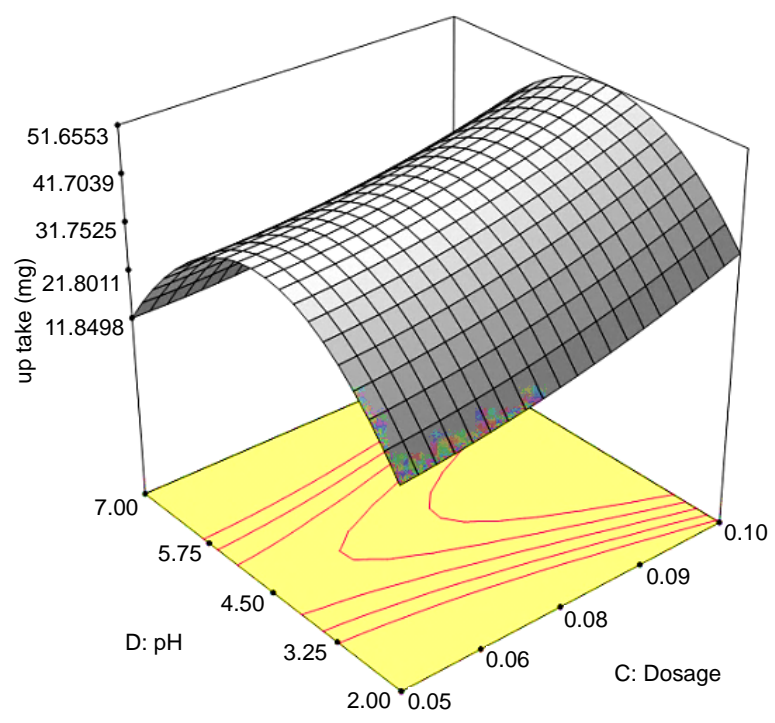

(d)

Figure 6. Interaction effect between $\mathrm{pH}$ and other variables on the required responses (a) $\mathrm{pH}$ and contact time (b) $\mathrm{pH}$ and initial concentration, (c) $\mathrm{pH}$ and initial concentration on the removal efficiency, (d) $\mathrm{pH}$ and dose.

5) Interaction between contact time and initial concentrations

The interaction between the contact time and the initial phosphate concentration was investigated at $\mathrm{pH} 4.5$ and dosage $0.08 \mathrm{gm}$ and represented in Figure 7(b). From Figure 7(b), the amount of the adsorbed phosphate increases with the contact time at any given concentration, but the effect of time increase to the maximum effect with increasing the initial phosphate concentration to the upper limit $(250 \mathrm{mg} / \mathrm{L})$. However the adsorption capacity increases with increasing the initial phosphate concentration at any given time, but the maximum effect occur after about $4.5 \mathrm{~h}$ and then the efficiency decreased.

Figure 7(c) represents the effect of time and concentration on the removal efficiency (\%). It is clear that the removal efficiency increase with time at any concentration, but it increase at lower concentrations and the maximum value occur at $50 \mathrm{mg} / \mathrm{L}$. $4.5 \mathrm{~h}$ contact time represent the best time for the removal efficiency. In the other hand the efficiency decrease with increasing the initial concentration to the minimum value at $250 \mathrm{mg} / \mathrm{L}$. the previous make $4.5 \mathrm{~h}$ as contact time and $50 \mathrm{mg} / \mathrm{L}$ as initial phosphate concentration the best conditions for maximum removal efficiency based on the upper and the lower limits of the selected parameters. 


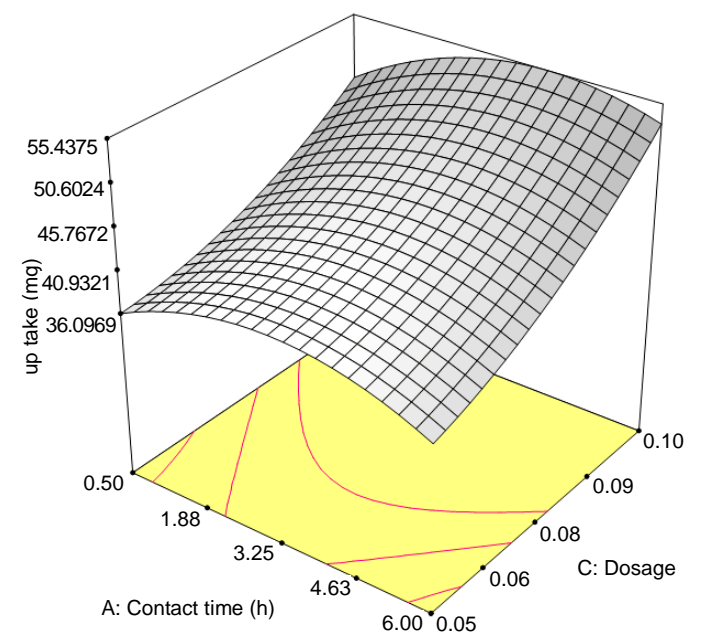

(a)

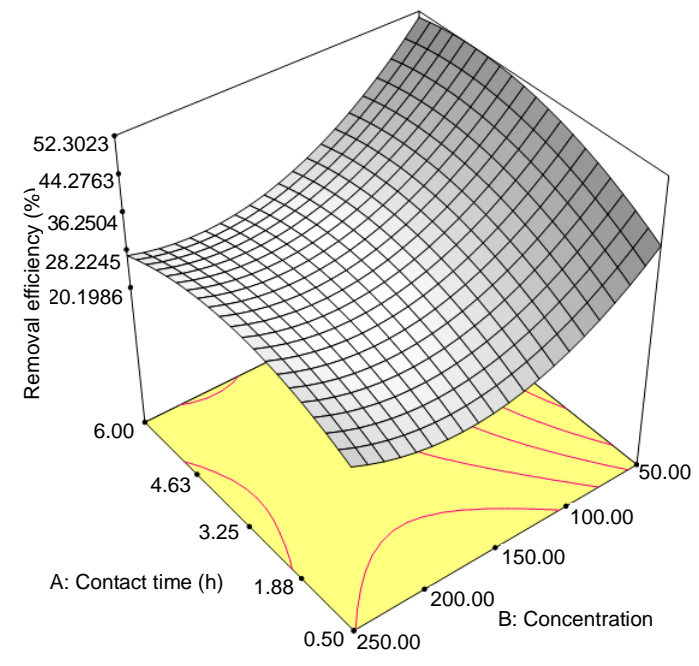

(c)

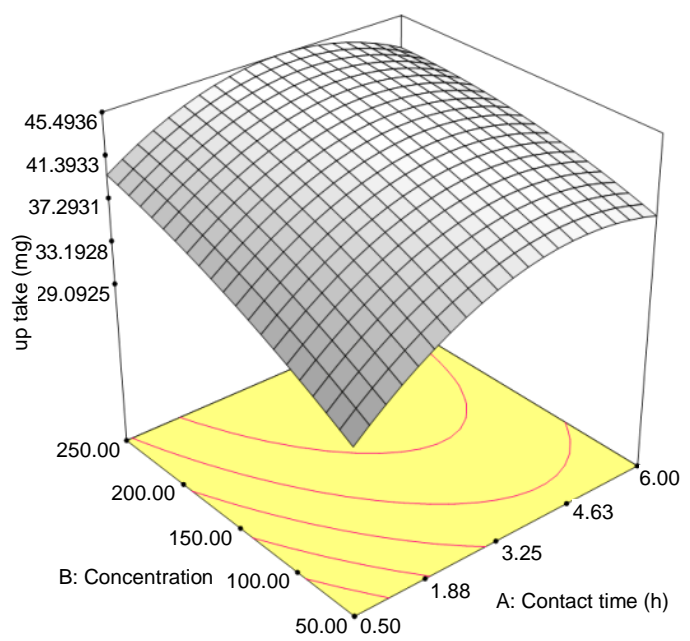

(b)

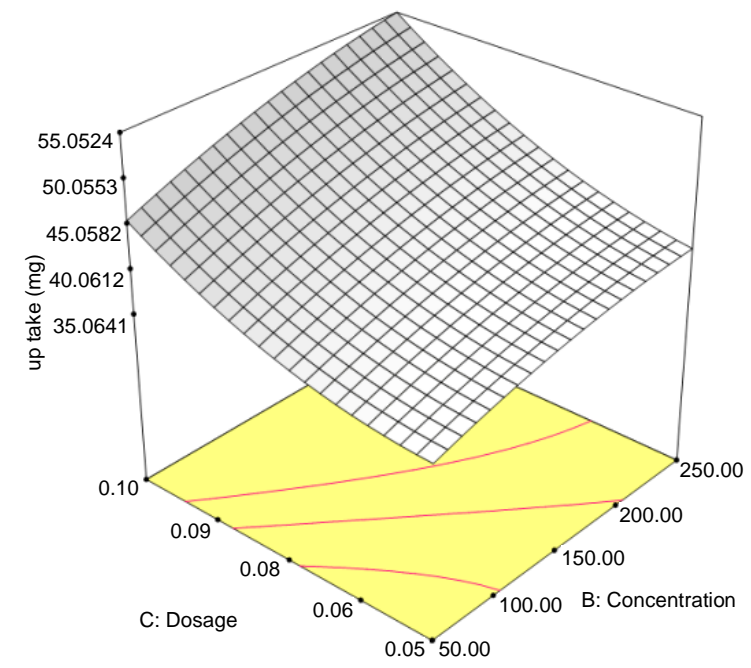

(d)

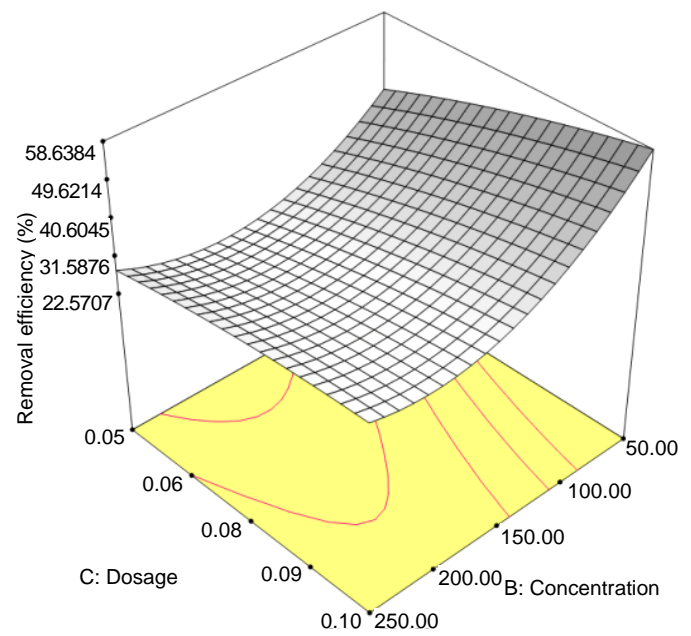

(e)

Figure 7. Interaction effect between the operating variables and the required responses. (a) Contact time and dosage; (b) Contact time and initial concentration; (c) Contact time and initial concentration on the removal efficiency; (d) Initial phosphate concentration and dose; (e) Initial phosphate concentration and dose on the removal efficiency. 
6) Interaction between dosage and the initial concentration

The relation between zeolite dosage and initial phosphate concentrations; and their effect on the required responses is represented in Figure 7(d) and Figure 7(e). This was performed at fixed $\mathrm{pH} 4.5$ and contact tome $3 \mathrm{~h}$. It is clear that, at any given initial phosphate concentration the amount of adsorbed phosphate $(\mathrm{mg} / \mathrm{g})$ increase with the amount of zeolite and the effect of the dose increase with increase the concentration to $250 \mathrm{mg} / \mathrm{L}$ (Figure $7(d)$ ). Also the removal efficiency increase with increasing the dose at any given concentration but appear to be more promising at lower concentrations (Figure 7(e)). Also the amount of adsorbed phosphate increase with increasing the initial concentrations at any given dose while the removal efficiency decrease with increasing the initial concentration and the best values obtained when the applied dose is the upper limit $(0.1 \mathrm{gm})$.

\section{Optimum Conditions}

Observed experimental results in Table 2 show that at $3 \mathrm{~h}$ as contact time, $150 \mathrm{mg} / \mathrm{L}$ initial phosphate concentration in the aqueous solution, 0.1 gm solid dose and $\mathrm{pH}_{4}$ are the best conditions with respect amount of phosphate adsorbed by the synthetic zeolite Na-A (53 mg/g), but the maximum removal efficiency (60\%) occur after $3 \mathrm{~h}$ as contact time, $50 \mathrm{mg} / \mathrm{L}$ initial concentration for phosphate in the aqueous solutions, $0.08 \mathrm{gm}$ dose and $\mathrm{pH}_{4}$.

The predicted optimum conditions for maximum phosphate anions removal using synthetic zeolite Na-A have been predicted using Design Expert's optimization function in terms of the upper and lower limits for the selected variables (contact time, initial concentrations, dose and $\mathrm{pH}$ ). The optimum conditions are listed in Table 4 and Table 5 with their predicted values. $4.5 \mathrm{~h}$ contact time, $50 \mathrm{ppm}$ initial concentration, 0.1 zeolite dose and $\mathrm{pH}$ 4.04 are the optimum conditions for maximum removal of phosphate (\%) by synthetic zeolite Na-A with predicted removal efficiency $61.77 \%$. While contact time of 4.52 h, $250 \mathrm{mg} / \mathrm{L}$ initial phosphate concentration, 0.1 zeolite Na-A dose and $4.14 \mathrm{pH}$ are the predicted optimum conditions for the maximum adsorption of phosphate anions $(55.82 \mathrm{mg} / \mathrm{g})$.

\section{Conclusions}

Highly crystalline synthetic Na-A was synthesized from Egyptian kaolinite by hydrothermal treatment of metakaolinite at $100^{\circ} \mathrm{C}$ for $8 \mathrm{~h}$. In this study, response surface methodology in conjunction with central composite rotatable design was employed for modeling and optimizing four operations parameters of phosphate removal using synthetic zeolite Na-A. Four variables of the model investigated in this study were: contact time, initial phosphate concentration, amount of zeolite and $\mathrm{pH}$ values. The mathematical model equations were derived for both amount of phosphate adsorbed (mg/g) and the removal efficiency (\%) from Design Expert Software (Version 6.0.5). Predicted values obtained using the model equations were in very good agreement with the observed values ( $R^{2}$ value of 0.918 for the amount of the adsorbed phosphate, $R^{2}$ value of 0.905 for the removal efficiency (\%)).

In order to gain a better understanding of the effects of these operational variables and their interactions on the amount of adsorbed phosphate (mg/g) and the removal efficiency (\%), the predicted models values were

Table 4. Predicted optimizes solutions for phosphate removal by synthetic Na-A zeolite.

\begin{tabular}{cccccc}
\hline Contact time (h) & Initial concentration (mg) & Dose (gm) & $\mathbf{p H}$ & Removal efficiency (\%) & Desirability \\
\hline $\mathbf{4 . 5}$ & 50 & 0.1 & 4.04 & 61.77 & 0.996 \\
$\mathbf{4 . 3 2}$ & 50 & 0.1 & 3.98 & 61.38 & 0.989 \\
$\mathbf{4 . 5}$ & 54.11 & 0.1 & 4.02 & 60.33 & 0.972 \\
\hline
\end{tabular}

Table 5. Predicted optimizes solutions for phosphate removal by synthetic Na-A zeolite.

\begin{tabular}{ccc|ccc}
\hline Contact time (h) & Initial concentration (mg) & Dose (gm) & $\mathbf{p H}$ & Amount of phosphate adsorbed (mg/g) & Desirability \\
\hline $\mathbf{4 . 5 5}$ & 250 & 0.1 & 4.19 & 55.82 & 0.997 \\
$\mathbf{4 . 4 3}$ & 250 & 0.1 & 4.21 & 55.81 & 0.996 \\
$\mathbf{4 . 4}$ & 250 & 0.1 & 4.24 & 55.71 & 0.994 \\
\hline
\end{tabular}


presented as cube and 3D response surface graphs. Taking advantage of the quadratic programming, contact time of $4.5 \mathrm{~h}$, initial concentration of $50 \mathrm{ppm}$, zeolite dose of $0.1 \mathrm{gm}$ and $\mathrm{pH}$ of 4.04 have been determined as optimum levels to achieve the maximum removal of phosphate of $61.77 \%$, whereas it is $60 \%$ in the tests conducted, i.e. 1.77 improvements in the removal efficiency could be obtained by the statistical design. In the same way, contact time of $4.52 \mathrm{~h}$, initial concentration of $250 \mathrm{ppm}$, zeolite dose of $0.1 \mathrm{gm}$ and $\mathrm{pH}$ of 4.19 have been determined as optimum levels to achieve the maximum amount of phosphate anions adsorbed by synthetic zeolite Na-A as it reaches (55.82 mg/g); however, the best result from the experimental tests is (53 mg/g).

\section{References}

[1] Ramakrishnaiah, C.R. and Vismitha (2012) Removal of Phosphate from Waste Water Using Low-Cost Adsorbents. International Journal of Engineering Inventions, 1, 44-50.

[2] De-Bashan, L.E. and Bashan, Y. (2004) Recent Advances in Removing Phosphorus from Wastewater and Its Future Use as Fertilizer. Water Research, 38, 4222-4246. http://dx.doi.org/10.1016/j.watres.2004.07.014

[3] El Sergany, M. and Shanableh, A. (2012) Phosphorus Removal Using Al-Modified Bentonite Clay-Effect of Particle Size. Proceeding Asia Pacific Conference on Environmental Science and Technology, 6, 323-329.

[4] Luo, H., Li, F., Zeng, Y.-M., Zhang, K. and Huang, B. (2012) Adsorption Control Performance of Phosphorus Removal from Agricultural Non-Point Source Pollution by Nano-Aperture Lanthanum-Modified Active Alumina. Advance Journal of Food Science and Technology, 4, 337-343.

[5] Xiong, W. (2009) Development and Application of Ferrihydrite Modified Diatomite and Gypsum for Phosphorus Control in Lakes and Reservoirs. Ph.D. Dissertation, College of Graduate Studies and Research, Saskatchewan, Canada.

[6] Quan, W.M. and Yan, L.J. (2002) Effects of Agricultural Non-Point Source Pollution on Eutrophication of Water Body and Its Control Measure. Acta Ecologica Sinica, 22, 291-299.

[7] Tang, H., Xiong, L.J. and Huang, S.F. (2011) Review on the Characteristic and Control Measurement of Agriculture Non-Point Source Pollution. Environmental Science \& Technology, 34, 107-112.

[8] Xie, T., Kang, C.X. and Tang, W.K. (2010) Review on the Pollution and Control Measurement of Agriculture NonPoint Source Pollution. Journal of Guangxi Teachers Education University (Natural Science Edition), 27, 70-73.

[9] Durán, N., Marcarto, P.D., De Souza, G.I.H., Alves, O.L. and Esposito, E. (2007) Antibacterial Effect of Silver Nanoparticles Produced by Fungal Process on Textile Fabrics and Their Effluent Treatment. Journal of Biomedical Nanotechnology, 3, 203-208. http://dx.doi.org/10.1166/jbn.2007.022

[10] Karapinar, N. (2009) Application of Natural Zeolite for Phosphorus and Ammonium Removal from Aqueous Solutions. Journal of Hazardous Materials, 170, 1186-1191. http://dx.doi.org/10.1016/j.jhazmat.2009.05.094

[11] Stratful, I., Brett, S., Scrimshaw, M.B. and Lester, J.N. (1999) Biological Phosphorus Removal, Its Role in Phosphorus Recycling. Environmental Technology, 20, 681-695. http://dx.doi.org/10.1080/09593332008616863

[12] Hart, B.T., Roberts, S., James, R., O’Donohue, M., Taylor, J. and Donner, D. (2003) Active Barrier to Reduce Phosphorus Release from Sediments: Effectiveness of Three Forms of $\mathrm{CaCO}_{3}$. Australian Journal of Chemistry, 56, 207217. http://dx.doi.org/10.1071/CH02232

[13] Drizo, A., Frost, C.A., Grace, J. and Smith, J.K. (1999) Physico-Chemical Screening of Phosphate Removing Substrates for Use in Constructed Wetland Systems. Water Research, 33, 3595-3602. http://dx.doi.org/10.1016/S0043-1354(99)00082-2

[14] Wadpersdolf, E., Neumann, T. and Stuben, D. (2004) Efficiency of Natural Calcite Precipitation Compared to Lake Marl Application Used for Water Quality Improvement in an Eutrophic Lake. Applied Geochemistry, 19, 1687-1698. http://dx.doi.org/10.1016/j.apgeochem.2004.04.007

[15] Xiong, W.H. and Peng, J. (2008) Development and Characterization of Ferrihydrite-Modified Diatomite as a Phosphorus Adsorbent. Water Research, 42, 4869-4877. http://dx.doi.org/10.1016/j.watres.2008.09.030

[16] Chaisena, A. and Rangsriwatananon, K. (2005) Synthesis of Sodium Zeolite from Natural and Modified Diatomite. Materials Letters, 59, 1474-1479. http://dx.doi.org/10.1016/j.matlet.2004.10.073

[17] Breck, D.W. (1974) Zeolite Molecular Sieves: Structure, Chemistry and Use. John Wiley, New York.

[18] Bowman, R.S. (2003) Application of Surfactant Modified Zeolites to Environmental Remediation. Microporous and Mesoporous Materials, 61, 43-56. http://dx.doi.org/10.1016/S1387-1811(03)00354-8

[19] Youssef, H., Ibrahim, D. and Komarneni, S. (2008) Microwave Assisted versus Conventional Synthesis of Zeolite A from Metakaolinite. Microporous and Mesoporous Materials, 115, 527-534. http://dx.doi.org/10.1016/j.micromeso.2008.02.030

[20] Mousavi, S.F., Jafari, M., Kazemimoghadam, M. and Mohammadi, T. (2013) Template Free Crystallization of Zeolite 
Rho via Hydrothermal Synthesis: Effects of Synthesis Time, Synthesis Temperature, Water Content and Alkalinity. Ceramic International, 39, 7149-7158. http://dx.doi.org/10.1016/j.ceramint.2013.02.058

[21] Katsuki, H., Furuta, S., Watari, T. and Komarneni, S. (2005) ZSM-5 Zeolite/Porous Carbon Composite: Conventionaland Microwave-Hydrothermal Synthesis from Carbonized Rice Husk. Microporous and Mesoporous Materials, 86, 145-151. http://dx.doi.org/10.1016/j.micromeso.2005.07.010

[22] Ma, Y., Alshameri, A., Qiu, X., Zhou, C. and Li, A. (2014) Synthesis and Characterization of 13X Zeolite from Low Grade Natural Kaolinite. Advanced Powder Technology, 25, 495-499. http://dx.doi.org/10.1016/j.apt.2013.08.002

[23] Belviso, C., Cavalcante, F., Lettino, A. and Fiore, S. (2013) A and X Type Zeolites from Kaolinite at Low Temperature. Applied Clay Science, 80, 162-168. http://dx.doi.org/10.1016/j.clay.2013.02.003

[24] Cheng, Y., Lu, M., Li, J., Su, X., Pan, S., Jiao, C. and Feng, M. (2012) Synthesis of MCM-22 Source under VaryingTemperature Conditions. Journal of Colloid and Interface Science, 369, 388-394. http://dx.doi.org/10.1016/j.jcis.2011.12.024

[25] Atta, A.Y., Jibril, B.Y., Aderemi, B.O. and Adefila, S.S. (2012) Preparation of Analcime from Local Kaolin and Rice Husk Ash. Applied Clay Science, 61, 8-13. http://dx.doi.org/10.1016/j.clay.2012.02.018

[26] Qiu, W. and Zheng, Y. (2009) Removal of Copper, Nickel, Cobalt and Zinc from Water by a Cancrinite-Type Zeolite Synthesized from Fly Ash. Chemical Engineering Journal, 145, 483-488. http://dx.doi.org/10.1016/j.cej.2008.05.001

[27] Wajima, T., Haga, M., Kuzawa, K., Ishimoto, H., Tamada, O., Ito, K., Nishiyama, T., Downs, R.T. and Rakovan, J.T. (2006) Zeolite Synthesis from Paper Sludge Ash at Low Temperature $\left(90^{\circ} \mathrm{C}\right)$ with Addition of Diatomite. Journal of Hazardous Materials, 132, 244-252. http://dx.doi.org/10.1016/j.jhazmat.2005.09.045

[28] Petkowicz, D.I., Rigo, R.T., Radtke, C., Pergher, S.B. and Dos-Santos, J.H.Z. (2008) Zeolite NaA from Brazilian Chrysotile and Rice Husk. Microporous and Mesoporous Materials, 116, 548-554. http://dx.doi.org/10.1016/j.micromeso.2008.05.014

[29] Liu, H., Shen, T., Yuan, P., Shi, G. and Bao, X. (2014) Green Synthesis of Zeolites from a Natural Aluminosilicate Mineral Rectorite: Effects of Thermal Treatment Temperature. Applied Clay Science, 90, 53-60. http://dx.doi.org/10.1016/j.clay.2014.01.006

[30] Liu, X.-D., Wang, Y.-P., Cui, X.-M., He, Y. and Mao, J. (2013) Influence of Synthesis Parameters on NaA Zeolite Crystal. Powder Technology, 243, 184-193. http://dx.doi.org/10.1016/j.powtec.2013.03.048

[31] Rege, S.U. and Yang, R.T. (1997) Limits for Air Separation by Adsorption with LiX Zeolite. Industrial \& Engineering Chemistry Research, 36, 5358. http://dx.doi.org/10.1021/ie9705214

[32] Eken-Saracoglu, N. and Culfaz, N. (1999) Clinoptilotile Zeolite as a Builder in Nonphosphated Detergents. Journal of Environmental Science and Health-Part A, 34, 1619-1626. http://dx.doi.org/10.1080/10934529909376916

[33] Ravikumar, K., Krishnan, S., Ramalingam, S. and Balu, K. (2007) Optimization of Process Variables by the Application of Response Surface Methodology for Dye Removal Using a Novel Adsorbent. Dyes and Pigments, 72, 66-74. http://dx.doi.org/10.1016/j.dyepig.2005.07.018

[34] Myers, R.H. and Montgomery, D.C. (2002) Response Surface Methodology. John Wiley and Sons, New York.

[35] Nuran, B. (2007) The Response Surface Methodology. Master of Science in Applied Mathematics and Computer Science, PhD Dissertation, Faculty of the Indiana University, South Bend.

[36] Gunaraj, V. and Murugan, N. (1999) Application of Response Surface Methodologies for Predicting Weld Base Quality in Submerged Arc Welding of Pipes. Journal of Materials Processing Technology, 88, 266-275. http://dx.doi.org/10.1016/S0924-0136(98)00405-1

[37] Box, G.E.P. and Wilson, K.B. (1951) On the Experimental Attainment of Optimum Conditions. Journal of the Royal Statistical Society, 13, 1-45.

[38] Box, G.E.P. and Hunter, W.G. (1957) Multi-Factor Experimental Design for Exploring Response Surfaces. Mathematical Statistics, 28, 195-241. http://dx.doi.org/10.1214/aoms/1177707047

[39] Obeng, D.P., Morrell, S. and Napier-Munn, T.J. (2005) Application of Central Composite Rotatable Design to Modeling the Effect of Some Operating Variables on the Performance of the Three-Product Cyclone. International Journal of Mineral Processing, 76, 181-192. http://dx.doi.org/10.1016/j.minpro.2005.01.002

[40] Cilliers, J.J., Austin, R.C. and Tucker, J.P. (1992) An Evaluation of Formal Experimental Design Procedures for Hydrocyclone Modeling. Proceeding of the 4th International Conference on Hydrocyclones, Southampton, 23-25 September 1992, 3-49.

[41] Souzaa, A.S., Walter, N.L., dos Santos, L.C. and Ferreira, S. (2005) Application of Box-Behnken Design in the Optimization of an On-Line Pre-Concentration System Using Knotted Reactor for Cadmium Determination by Flame Atomic Absorption Spectrometry. Spectrochimica Acta, Part B: Atomic Spectroscopy, 60, 737-742. http://dx.doi.org/10.1016/j.sab.2005.02.007 
[42] Ferreira, A.C., Costa, A.C.S. and Korn, M.G.A. (2004) Preliminary Evaluation of the Cadmium Concentration in Sea Water of the Salvador City, Brazil. Microchemical Journal, 78, 77-83. http://dx.doi.org/10.1016/j.microc.2004.03.014

[43] Gougazeh, M. and Buhl, J.C. (2014) Synthesis and Characterization of Zeolite A by Hydrothermal Transformation of Natural Jourdanian Kaolin. Journal of the Association of Arab Universities for Basic and Applied Sciences, 15, 35-42. http://dx.doi.org/10.1016/j.jaubas.2013.03.007

[44] Treacy, M.M.J. and Higgins, J.B. (2001) Collection of Simulated XRD Powder Patterns for Zeolites. Elsevier, Amsterdam.

[45] Rajasimman, M. and Murugaiyan, K. (2012) Application of the Statistical Design for the Sorption of Lead by Hypneavalentiae. Journal of Advanced Chemical Engineering, 2, 1-7.

[46] Deepa, C.N., Sayed, A. and Suresha, S. (2014) Kinrtic and Isothermal Studies on the Removal of Copper (П) from Aqueous Solution by Araucaria Cook П: Response Surface Methodology for the Optimization. International Journal of Recent Scientific Research, 5, 820-827.

[47] Chen, J.C., Kong, H.N., Wu, D.Y., Hu, Z.B., Wang, Z.S. and Wang, Y.H. (2006) Removal of Phosphate from Aqueous Solution by Zeolite Synthesized from Fly Ash. Journal of Colloid and Interface Science, 300, 491-497. http://dx.doi.org/10.1016/j.jcis.2006.04.010

[48] Hamdi, N. and Srasra, E. (2012) Removal of Phosphate Ions from Aqueous Solution using Tunisian Clays Minerals and Synthetic Zeolite. Journal of Environmental Sciences, 24, 617-623. http://dx.doi.org/10.1016/S1001-0742(11)60791-2

[49] Akar, T. and Tunali, S. (2006) Biosorption Characteristics of Aspergillus flavus Biomass for Removal of $\mathrm{Pb}$ (II) and Cu (II) Ions from Aqueous Solution. Bioresource Technology, 97, 1780-1787. http://dx.doi.org/10.1016/j.biortech.2005.09.009

[50] Mall, D.I., Srivastava, V.C. and Agarwal, N.K. (2006) Removal of Orange-G and Methyl Violet Dyes by Adsorption onto Bagasse Fly Ash-Kinetic Study and Equilibrium Isotherm Analyses. Dyes and Pigments, 69, 210-223. http://dx.doi.org/10.1016/j.dyepig.2005.03.013 